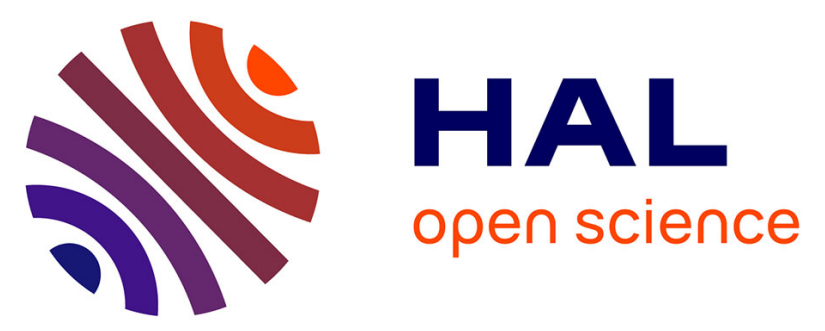

\title{
Phase I/II study on docetaxel, gemcitabine and prednisone in castrate refractory metastatic prostate cancer
}

\author{
Trine Zeeberg Buch-Hansen, Lise Bentzen, Steinbjoern Hansen, Morten \\ Hoeyer, Niels Viggo Jensen, Charlotte Saxe, Lisa Sengeloev
}

\section{To cite this version:}

Trine Zeeberg Buch-Hansen, Lise Bentzen, Steinbjoern Hansen, Morten Hoeyer, Niels Viggo Jensen, et al.. Phase I/II study on docetaxel, gemcitabine and prednisone in castrate refractory metastatic prostate cancer. Cancer Chemotherapy and Pharmacology, 2009, 66 (2), pp.295-301. 10.1007/s00280009-1163-x . hal-00568275

\section{HAL Id: hal-00568275 \\ https://hal.science/hal-00568275}

Submitted on 23 Feb 2011

HAL is a multi-disciplinary open access archive for the deposit and dissemination of scientific research documents, whether they are published or not. The documents may come from teaching and research institutions in France or abroad, or from public or private research centers.
L'archive ouverte pluridisciplinaire HAL, est destinée au dépôt et à la diffusion de documents scientifiques de niveau recherche, publiés ou non, émanant des établissements d'enseignement et de recherche français ou étrangers, des laboratoires publics ou privés. 


\section{Phase I/II study on docetaxel, gemcitabine and}

\section{prednisone in castrate refractory metastatic prostate}

\section{cancer.}

*Trine Zeeberg Buch-Hansen ${ }^{1}$, Lise Bentzen ${ }^{2}$, Steinbjoern Hansen ${ }^{3}$, Morten Hoeyer ${ }^{2}$, Niels Viggo Jensen $^{3}$, Charlotte Saxe ${ }^{1}$, Lisa Sengeloev ${ }^{1}$

${ }^{1}$ Herlev University Hospital, Dept. of Oncology ${ }^{2}$ Aarhus University Hospital, Dept. of Oncology

${ }^{3}$ Odense University Hospital, Dept. of Oncology

* Corresponding author

* Trine Zeeberg Buch-Hansen, MD

Herlev University Hospital, Herlev Ringvej 75, DK - 2730 Herlev, Denmark

Department of Oncology; Phone: 004544884000 Ext. 89183

Fax number: 0045 44883010; Mail: trzebu01@heh.regionh.dk 
Phase I/II study on docetaxel, gemcitabine and prednisone for treatment of castrate refractory metastatic

prostate cancer.

Authors: T. Z. Buch-Hansen, L. Bentzen, S. Hansen, M. Hoeyer, N. V. Jensen, C. Saxe, L. Sengeloev

Purpose: We assessed the efficacy and toxicity of a fixed dose of docetaxel and prednisone, combined with escalating doses of gemcitabine (DGP). The primary endpoint was PSA response.

Methods: Fifteen patients (pts) were enrolled in the phase I and 50 pts entered the phase II. Pts were given DGP, maximum of 8 courses, until progression or unacceptable toxicity. Docetaxel $75 \mathrm{mg} / \mathrm{m}^{2}$ was administered intravenously day 1 , gemcitabine was given day 1 and 8 in doses increasing from 600 to $1,000 \mathrm{mg} / \mathrm{m}^{2}$ every third week. Pts had castrate refractory metastatic prostate cancer (CRMPC), adequate function of liver, kidney and bone marrow; ECOG performance status $\leq 2$ and were chemotherapy-naïve.

Results: Median age was 64 range (49-77). Twenty-one (42\%) were PS 0, 26 (52\%) were PS 1 and 3 (6\%) were PS 2 . The median pre-treatment PSA was 448 (12-4.580). No dose limiting toxicity was observed even with the highest dose level in the phase I part of the study. In the phase II part, PSA response was observed in $37(74 \%)$ pts. Twenty-four (48\%) pts had measurable disease; 12 (50\%) had partial remission, 5 (21\%) had stable disease, 7 (29\%) were not evaluable. Time to progression (TTP) was 7.9 months and overall survival (OS) was 13.9 months. Thirty-seven pts (74\%) developed neutropenia, non-haematological toxicity was modest.

Conclusions: The PSA response rate was promising and the toxicity of DGP was manageable; however OS was comparable to results of treatment with single agent docetaxel.

Keywords: PSA response, palliation, chemotherapy, pain. 


\section{Introduction:}

Prostate cancer (PC) is the most frequent cancer in men and one of the most common cancer-related causes of death in men in the Western World [1]. There is a large variability in response to anticancer therapy in prostate cancer. Most cancers are sensitive to treatment with hormones, although they all within time become insensitive or independent to hormone therapy. Similar to other solid tumours, PC has recently been found to be sensitive to treatment with chemotherapy [2]. Castrate refractory PC is defined as that state of disease, where clinical progression and/or increasing PSA is observed, in spite of castrate level of plasma-testosterone. Patients with castrate-refractory metastatic prostate cancer (CRMPC) typically have a median survival of 12-18 months [3]. Men with metastatic PC often suffer from skeletal pain-, fractures, haematological consequences of marrow infiltration, neurological impairment and cord compression emphasizing that palliation is an important parameter in treatment [4].

Treatments of metastatic PC comprise hormone therapy, chemotherapy, palliative radiation therapy, isotope treatment and bisphosphonates plus experimental treatments. Tannock et al demonstrated that a combination of mitoxantrone and prednisone had a superior palliative response compared to single-agent treatment with prednisone [5]. A new era in the treatment of CRMPC was opened by the TAX327 study demonstrating that overall survival was significantly longer and quality of life improved with a docetaxel-based regime given in a 3-week schedule compared to mitoxantrone [6, 7]. This was confirmed by the SWOG 9916 trial where overall survival was significantly longer in the docetaxel-arm [8]. The two studies proved that chemotherapy in CRMPC patients prolonged overall survival.

The combination docetaxel, gemcitabine and prednisone (DGP) chemotherapy has been successful in treatment of other solid tumours. Laufman et al concluded that monthly docetaxel combined with weekly gemcitabine was effective in metastatic breast cancer, resulting in high response rates, durable responses and was associated with favourable survival [9]. Hejna et al assessed the regimen Docetaxel, Gemcitabine and granulocyte-colony stimulating factor in treatment of advanced non-small cell lung carcinoma and found this treatment to have significant activity [10]. In the treatment of CRMPC Morant et al showed that single agent gemcitabine had a significant beneficial impact on pain despite its limited efficacy in terms of PSA response [11]. However, there is only limited literature available on the anti-tumour efficacy and tolerance of DGP to treatment of CRMPC. As suggested by Roth et al, combining a taxane with an antimicrotubuli agent, this treatment might have different mechanisms of action on tumour-cells, thereby leaving the possibility of additive or even synergistic effect $[12,13]$. 
In this study we aimed to assess the toxicity and efficacy of the combination of DGP in patients with CRMPC. By combining docetaxel and gemcitabine we hoped to augment the rate of response and ameliorate palliation for patients with metastatic PC. The study was planned as a dose-escalating phase I followed by a phase II, where the primary endpoint was PSA response with overall survival, palliation effects, and toxicity being secondary end points. 


\section{Material and methods:}

\section{Design}

Our study was an open-label multicenter phase I/II design, carried out by three Departments of Oncology in Denmark, each including about one third of the enrolled patients. In the phase I study 15 patients were included; each dose levels (0-4) of DGP were given to 3 patients. The 3 patients receiving dose level 4 were analyzed together with the 47 patients included in the phase II part, giving a total of 50 patients in the phase II. Descriptive statistics were applied to describe the observed toxicity during the study. In phase I, dose limiting toxicity (DLT) was defined as Chemotherapy Toxicity Criteria (CTC) grade 4 of both haematological and non-haematological side effects, fever and neutropenia grade 3-4 $\geq 5$ days, or CTC grade $\geq 2$ lung toxicity. The aim of the phase I was to define the maximum tolerated dose (MTD) of DGP, Table 1A. Three patients were included in dose level 0, if DLT had occurred the treatment would have been reduced to dose level -1. If one patient developed DLT, 3 extra patients would have been included in this particular dose level, and if none of them had developed DLT, then another 3 patients could be included in the next dose level. MTD was defined as the dose level below DLT. The MTD of DGP was defined to be docetaxel $75 \mathrm{mg} / \mathrm{m} 2$ and gemcitabine $1,000 \mathrm{mg} / \mathrm{m} 2$ and was used in the phase II. Patients were enrolled in the period between December 2004 and December 2006 with a follow up period of minimum 1 year.

\section{Study population}

Eligible patients had histological verified adenocarcinoma of the prostate with either radiological or clinical evidence of metastatic disease. Patients had to have symptomatic CRMPC, castrate level of testosterone $(<0.5$ nmol/L); castration could be due to either orchidectomy or treatment with LHRH agonists. CRMPC was defined as being in clinical and biochemical progression despite castration and addition of anti-androgen and subsequent withdrawal of the antiandrogen. Anti-androgens had to be stopped at least four weeks before entering the study. PSA should be at least 10 microgram/l, and no previous treatment with oestrogen or steroids for metastatic disease was allowed. Patients should have sufficient function of liver, kidneys and bone marrow. Patients had to be in ECOG performance status $\leq 2$ and life expectancy had to be at least 3 months. Patients with symptomatic brain metastasis, or concurrent serious medical condition were excluded. All patients provided written informed consent; the study was carried out according to the Helsinki Declaration II and individual patient data were monitored according to international standards of good clinical practice. The protocol was approved by the Ethics Committee of Copenhagen County (KA 04122 gms 12.17.2004). 


\section{Chemotherapy}

The DGP was administrated in cycles of 3 weeks. Docetaxel (Taxotere, Sanofi-Aventis, Denmark) was given as a onehour infusion day 1 and gemcitabine (Gemzar, Eli Lilly, Denmark) infusion over 30 minutes day 1 and 8. Patients received $5 \mathrm{mg}$ of oral prednisone twice daily, continuously and all patients received pre-medication in the form of oral prednisone $50 \mathrm{mg} \mathrm{12,3}$ and 1 hour before infusion of docetaxel. Anti-emetics were prescribed according to local practice in the three participating departments. Each patient could receive a maximum of 8 courses, and treatment was stopped if progression or unacceptable toxicity were registered. Patients who discontinued due to toxicity were followed for 30 days after last chemotherapy. Haematopoietic growth factors were not used. Treatment on day 1 was delayed if WBC $\leq 3 * 10^{9} / 1$, neutrophil count $\leq 1.5 * 10^{9} / 1$ or platelet counts $\leq 100^{*} 10^{9} / 1$ whereas the dose was reduced in case of insufficient haematological status on day 1 , day 8 or at nadir. Patients were examined at start of each cycle where clinical evaluation of the non-haematological toxicity was also registered. Non-haematological toxicity rated by CTC grade 1-4 (NCI; CTCAE version 3.0, Dec. 2003) could if necessary result in dose reduction.

\section{Endpoints}

The primary endpoint in the phase I part was to determine the MTD of the combination of DGP in treatment of CRMPC. Primary endpoint in the phase II part was PSA response. The level of PSA was measured before entering study, and used as baseline for evaluation of response. According to Bubley et al, PSA response is defined as a reduction of $\geq 50 \%$ compared to baseline level, verified by a second measurement at least 4 weeks later [14]. PSA progression was defined as a rise in PSA level of $\geq 25 \%$, though at least 5 microgram $/ \mathrm{L}$, and verified by a second measurement. Response rates in patients with measurable disease were evaluated regarding to the RECIST criteria. Secondary endpoints were time to progression (TTP) and toxicity. TTP was calculated from inclusion until PSA progression, clinical progression or cancer-related death. Furthermore, the study aimed to evaluate the palliative response, defined as reduction in pain after 4 and 8 courses of treatment. Toxicity was evaluated by the CTCAE version 3.0 grading system. Patients recorded the presence of pain and the consumption of analgesics (opioids and non-opioids) on daily basis in a dedicated diary during the course of chemotherapy. Grading of fatigue and pain was done by the 


\section{Statistical analysis}

In the phase II part, a two-step design was carried out leaving the possibility to stop the study early, if treatment with DGP proved to be ineffective or encumbered with unacceptable toxicity. Serious adverse events, laboratory tests and objective response were summarized by the use of descriptive statistics during study. This design consequently gives 0.66 chances to stop the study at the first step, if response rates were less than 20 percent $\left(\mathrm{H}_{0}\right)$ and a probability of 0.095 to stop early if the true rate of response was 40 percent $\left(\mathrm{H}_{\mathrm{a}}\right)$. The statistical power was more than $90 \%$ if tumour response rate exceeded 40\%. TTP and overall survival (OS) were calculated by the method of Kaplan-Meier. Pain and fatigue response were analysed by two times two-tables and Pearson's $\chi^{2}$ test. $P$-values $\leq .05$ were considered of statistical significance. 


\section{$\underline{\text { Results: }}$}

\section{Patient characteristics}

Fifteen patients were included in the phase I part in the period of December 2004 - December 2006. For patient characteristics, see Table 1B. Haematological and non-haematological side effects were modest, no CTC grade 4 toxicity was registered, see Table 1C. No fever and neutropenia occurred, 2 patients had anaemia CTC grade 2 and 1 patient developed thrombocytopenia CTC grade 2; the haematological toxicity were manageable. Adverse events were seen in 2 patients suffering from anaemia and hospitalized for blood transfusion, 1 patient with thrombosis in the eye, subsequently treated with anti-coagulants, and 1 patient was hospitalized due to pathological fracture. One patient developed lung fibrosis after 4 courses of DGP. Since lung fibrosis has been reported as a possible side effect to gemcitabine, although rare, this patient discontinued treatment. Reduction in PSA $\geq 50 \%<75 \%$ was seen in 4 patients $(27 \%)$, whereas PSA reduction $\geq 75 \%$ was observed in 10 patients $(67 \%), 1$ patient did not respond in terms of PSA.

Fifty patients were enrolled in the phase II, part of which three patients were recruited from the phase I part. Prior local treatment at Department of Urology was radical prostatectomy $(\mathrm{n}=2)$ or radiation therapy $(\mathrm{n}=1)$. In 16 patients $(32 \%)$ data on gleason score and prior local treatment were unfortunately not available. For patient characteristics for patients included in the phase II, see Table 2.

\section{Toxicity and dose modification}

The treatment with DGP was generally well tolerated, side effects were manageable, and no toxicity-related deaths were observed. Alopecia CTC grade 1 or 2 was registered in 8 patients in phase I and in 35 patients in the phase II part, giving a total of $69 \%$ of patients. Due to neutropenia, 36 patients received no treatment at day 8 at least once, and these patients received no gemcitabine on day 8 with a mean of 3 times during study time. Nine patients had dose reductions of DGP at day 1 or 8 primarily because of fever and neutropenia grade 3-4 prior to treatment, or neuropathy grade 3 . Delays in treatment were seen in 5 patients. In total 18 patients had serious adverse events; 7 had fever and neutropenia, 5 were hospitalized and treated for infection, 1 patient had a myocardial infarction treated with percutaneous coronary intervention, and 1 patient was observed for pulmonary and peripheral oedema. One patient developed lung-fibrosis and 1 patient was treated for bilateral pleuritis, both possibly related to gemcitabine and these two patients discontinued 
treatment. Most frequent haematological toxicity grade 3-4 was neutropenia, where as non-haematological side effects grade 3-4 was modest, Table 3.

\section{Effect of treatment}

Biochemical response defined as $\geq 50 \%$ reduction of PSA was observed in 37 patients (74\%) confidence interval (CI) 59.7\%-85.4\% patients, whereas major PSA response of $\geq 75 \%$ was registered in 23 patients (46\%), Table 4 . We found statistical significant $(P=.049)$ association between pain grade and time, meaning that patients had reported less pain after eight courses of DGP, table 5. We also examined fatigue during study but found no statistical association between courses of chemotherapy and fatigue over time. The median TTP was 7.9 months with 95\%, CI 6.9-9.0 and median OS was 13.9 months, $95 \%$ CI 10.2-17.5, Fig.1. 


\section{Discussion:}

The aim of the present study was to investigate the efficacy and safety of docetaxel treatment combined with gemcitabine in the treatment of CRMPC patients. We found a high proportion of patients responding to DGP, 74\% responded with reduction in PSA $\geq 50 \%$, whereas $46 \%$ had PSA reduction $\geq 75 \%$. In the TAX 327 (docetaxel arm $75 \mathrm{mg} / \mathrm{m} 2$ given every third week $=B$-arm) they found response rates of PSA reduction $\geq 50 \%$ at $45 \%$ of the patients [6]. Similarly studies examining the efficacy of Docetaxel treatment have shown 50\% PSA response rates between 30\% - 70\%, emphasizing the high rate of PSA response we found in our study [13, 15]. In addition we found that a large proportion of patients with measurable disease obtained either partial remission $(50 \%)$ or stable disease $(20 \%)$, compared to Sinibaldi et al who reported partial remission in $25 \%$ of patients with measurable disease in CRMPC patients treated with docetaxel plus one-day oral estramustinephosphate [16].

Response to treatment was encouraging, although the time to progression and the overall survival we demonstrated was 13.9 months, compared to OS of 18.9 months in the Tax 327 B-arm [6]. The differences shown in TTP and OS might be due to the fact that, patients in our study had more advanced disease when entering study. We found a mean PSA of 448 microgram/L at baseline, compared to mean PSA of 114 microgram/L in the B-arm of TAX 327, suggesting that patients receiving DGP had poorer prognosis $[6,8,17]$. In our study $98 \%$ had bone metastasis and $56 \%$ had visceral metastasis, whereas patients in the B-arm of Tax 327 patients had bone involvement in $90 \%$ of cases and visceral metastasis in $22 \%$ of cases [6]. Measurable tumours were seen in $48 \%$ of DGP patients, whereas in Tax 327 B-arm $40 \%$ of patients had measurable lesions [6]. In our study an inclusion criteria for patients to receive DGP was symptomatic disease, thus all our patients had symptoms of CRMPC, which is different from the TAX 327 study. We also found that $42 \%$ of DGP patients had Gleason score 8-10, which was registered for $31 \%$ of the TAX 327 B-arm patients [6]. The abovementioned differences might explain the relative impaired OS found in the present study.

Patients were diagnosed with metastatic disease in average 22 months before enrolment, thus the DGP patients had extended disease for almost two years before given chemotherapy. When our study was initiated, docetaxel had recently become standard treatment of CRMPC. It is possible that overall survival would have been higher if patients were treated earlier, as also suggested by Roth et al [13]. For more accurate estimation of the efficacy of the DGP combination in patients with CRMPC a randomized phase III trial will have to be conducted. The role of combination chemotherapy for patients with CRMPC is still uncertain; we need further studies to differentiate what we gain from 
docetaxel treatment alone, and what a secondary chemotherapy offers to the patients in terms of longer survival, pain relief, toxicity etc.

Our study showed statistical significant reduction in pain for CRMPC patients when treated with eight courses of DGP, although only fifty patients were enrolled. The importance of pain as a statistically significant predictor of OS in men with CRMPC was demonstrated by Halabi et al [18]. Pain reduction after treatment with docetaxel was also demonstrated in the Tax 327 study [6].

The combination DGP was in general well-tolerated and side effects manageable. We found that treatment with gemcitabine at day 8 was not possible for about 3 cycles per patient, due to haematological toxicity, this being comparable to similar studies $[19,20]$. Haematological toxicity is an important issue in PC patients with bone metastasis and possible impaired bone marrow function, thereby limiting the ability of tolerating chemotherapy doublets or triplets, which must be taken into consideration when testing different regimes for this type of cancer [19, 21]. Hejna et al used routinely prophylactic administration of hematopoietic granulocyte-colony stimulating factor (G-CSF) in combination with docetaxel and gemcitabine in treatment of lung cancer patients, and showed that this treatment was effective in preventing and counteracting myelosuppression as dose-limiting toxicity [10]. The MTD of DG treatment chosen for the phase II study might retrospectively have been too high, due to the high proportion of patients developing neutropenia and therefore being forced to avoid, reduce or delay chemotherapy day 8 . Since we did not allow treatment with granulocyte-colony stimulating factor, we might have profited by using Gemcitabine $800 \mathrm{mg} / \mathrm{m} 2$.

Since we have found high response rates to treatment without improvement in overall survival, this raises the question whether PSA response has limited use in the prediction of survival in chemotherapy of CRMPC. The usefulness of PSA prediction of survival was questioned as well by Roth et al when discussing results of the TAX 327 and the SWOG study $[6,8,13]$. We believe that treatment with DGP is better than single agent docetaxel for patients with CRMPC, and hypothesise that, in a clinical setting in which DGP treatment is introduced immediately after the diagnosis of metastatic, CRPC disease, even if the patient being asymptomatic, the DGP treatment probably would improve overall survival and PSA response. Nobuyuki et al. reported that levels of PSA decreased by more than 50\% in $95 \%$ of patients with hormone refractory prostate cancer and a median overall survival of 26.6 months, when treated with docetaxel, 
estramustine phosphate and carpoplatin [22]. This study and similar phase II studies of combination chemotherapy for CRMPC patients have proven effective and with acceptable toxicity $[23,24]$ and thus warrants further studies. 


\section{Conclusion:}

We found promising biochemical and objective response as well as pain-reduction in CRMPC patients treated with a combination of docetaxel, prednisone and gemcitabine. Nevertheless, TTP and overall survival was not improved compared to results of mono-therapy with docetaxel. The combination was safe and tolerable. Further studies on the drug combination DGP are needed to clarify the relationship between PSA response and overall survival in patients with CRMPC. A randomized phase III study with single agent docetaxel compared to different regiments of combination chemotherapy for patients with CRMPC is warranted.

Acknowledgements: The study was supported by Sanofi-Aventis and Eli Lilly. Knud M. Nelausen from Dep. of Clinical Research / Dep. of Oncology R, Herlev University Hospital, contributed to statistical analysis in this article. 


\section{Reference List:}

1. Pienta KJ, Smith DC (2005) Advances in prostate cancer chemotherapy: a new era begins. CA Cancer J Clin $5: 300-18$

2. Ernst DS, Tannock IF, Winquist EW, Venner PM, Reyno L, Moore MJ et al (2003) Randomized, double-blind, controlled trial of mitoxantrone/prednisone and clodronate versus mitoxantrone/prednisone and placebo in patients with hormone-refractory prostate cancer and pain. J Clin Oncol 17:3335-42

3. Gravis G, Bladou F, Salem N, quart-Moulin G, Serment G, Camerlo J et al (2003) Weekly administration of docetaxel for symptomatic metastatic hormone-refractory prostate carcinoma. Cancer 8:1627-34

4. Morris MJ, Scher HI (2003) Clinical approaches to osseous metastases in prostate cancer. Oncologist 2:161-73

5. Tannock IF, Osoba D, Stockler MR, Ernst DS, Neville AJ, Moore MJ et al (1996) Chemotherapy with mitoxantrone plus prednisone or prednisone alone for symptomatic hormone-resistant prostate cancer: a Canadian randomized trial with palliative end points. J Clin Oncol 6:1756-64

6. Tannock IF, de WR, Berry WR, Horti J, Pluzanska A, Chi KN et al (2004) Docetaxel plus prednisone or mitoxantrone plus prednisone for advanced prostate cancer. N Engl J Med 15:1502-12

7. Berthold DR, Pond GR, de WR, Eisenberger M, Tannock IF (2008) Survival and PSA response of patients in the TAX 327 study who crossed over to receive docetaxel after mitoxantrone or vice versa. Ann Oncol 10:1749-53

8. Petrylak DP, Tangen CM, Hussain MH, Lara PN, Jr., Jones JA, Taplin ME et al (2004) Docetaxel and estramustine compared with mitoxantrone and prednisone for advanced refractory prostate cancer. N Engl J Med 15:1513-20

9. Laufman LR, Spiridonidis CH, Pritchard J, Roach R, Zangmeister J, Larrimer N et al (2001) Monthly docetaxel and weekly gemcitabine in metastatic breast cancer: a phase II trial. Ann Oncol 9:1259-64. 
10. Hejna M, Kornek GV, Raderer M, Ulrich-Pur H, Fiebiger WC, Marosi L et al (2000) Treatment of patients with advanced nonsmall cell lung carcinoma using docetaxel and gemcitabine plus granulocyte-colony stimulating factor. Cancer 3:516-22

11. Morant R, Bernhard J, Maibach R, Borner M, Fey MF, Thurlimann B et al (2000) Response and palliation in a phase II trial of gemcitabine in hormone-refractory metastatic prostatic carcinoma. Swiss Group for Clinical Cancer Research (SAKK). Ann Oncol 2:183-8

12. Speicher LA, Barone L, Tew KD (1992) Combined antimicrotubule activity of estramustine and taxol in human prostatic carcinoma cell lines. Cancer Res 16:4433-40

13. Roth BJ (2005) Prostate cancer chemotherapy: emerging from the shadows. J Clin Oncol 15:3302-3

14. Bubley GJ, Carducci M, Dahut W, Dawson N, Daliani D, Eisenberger M et al (1999) Eligibility and response guidelines for phase II clinical trials in androgen-independent prostate cancer: recommendations from the Prostate-Specific Antigen Working Group. J Clin Oncol 11:3461-7

15. Berry W, Eisenberger M (2005) Achieving treatment goals for hormone-refractory prostate cancer with chemotherapy. Oncologist 10:30-9

16. Sinibaldi VJ, Carducci MA, Moore-Cooper S, Laufer M, Zahurak M, Eisenberger MA (2002) Phase II evaluation of docetaxel plus one-day oral estramustine phosphate in the treatment of patients with androgen independent prostate carcinoma. Cancer 5:1457-65

17. Goodin S, Medina P, Capanna T, Shih WJ, Abraham S, Winnie J et al (2005) Effect of docetaxel in patients with hormone-dependent prostate-specific antigen progression after local therapy for prostate cancer. J Clin Oncol 15:3352-7

18. Halabi S, Vogelzang NJ, Kornblith AB, Ou SS, Kantoff PW, Dawson NA et al (2008) Pain predicts overall survival in men with metastatic castration-refractory prostate cancer. J Clin Oncol 15:2544-9

19. Rodney A, Dieringer P, Mathew P, Jonasch E, Tannir N, Pagliaro LC (2006) Phase II study of capecitabine combined with gemcitabine in the treatment of androgen-independent prostate cancer previously treated with taxanes. Cancer 10:2143-7 
20. Pagliaro LC, Delpassand ES, Williams D, Millikan RE, Tu SM, Logothetis CJ (2003) A Phase I/II study of strontium- 89 combined with gemcitabine in the treatment of patients with androgen independent prostate carcinoma and bone metastases. Cancer 12:2988-94

21. Beer TM, Eilers KM, Garzotto M, Egorin MJ, Lowe BA, Henner WD (2003) Weekly high-dose calcitriol and docetaxel in metastatic androgen-independent prostate cancer. J Clin Oncol 1:123-8

22. Kikuno N., Urakami S., Nakamura S., Hiraoka T., Hyuga T., Arichi N. et al. (2007) Phase II study of Docetaxel, Estramustine Phosphate, nad Carpoplatin in Patients with Hormone-Refractory Prostate Cancer. Eur Urol 51: 1252-1258

23. Nakabayashi M., Sartor O.,, Jacobus S., Regan M., Taplin M.E., Oh W.K. et al. (2008) Response to docetaxel/carpoplatin-based chemotherapy as first- and second-line therapy in patients with metastatic hormone-refractory prostate cancer. BJU Int.: 101, 308-312.

24. Oh W.K., Halabi S., Kelly W.K., Werner C., Godley P.A., Small E.J. et al. (2003) Cancer, Dec. 15, Vol. 98, no. 12. 
Table 1A - Dose steps Phase I

\begin{tabular}{|l|l|l|l|l|l|l|}
\hline Dose level & $\mathbf{- 1}$ & $\mathbf{0}$ & $\mathbf{1}$ & $\mathbf{2}$ & $\mathbf{3}$ & $\mathbf{4}$ \\
\hline $\begin{array}{l}\text { Docetaxel } \\
\mathrm{mg} / \mathrm{m}^{2}\end{array}$ & 60 & 75 & 75 & 75 & 75 & 75 \\
\hline $\begin{array}{l}\text { Prednisone } \\
\text { P.O. }\end{array}$ & $5 \mathrm{mg} * 2$ & $5 \mathrm{mg} * 2$ & $5 \mathrm{mg} * 2$ & $5 \mathrm{mg} * 2$ & $5 \mathrm{mg} * 2$ & $5 \mathrm{mg} * 2$ \\
\hline $\begin{array}{l}\text { Gemcitabine } \\
\mathrm{mg} / \mathrm{m}^{2}\end{array}$ & 450 & 600 & 700 & 800 & 900 & 1000 \\
\hline
\end{tabular}


Table 1B - Patient characteristics Phase I

\section{Table 1B - Patients characteristics (patient $\mathbf{n = 1 5}$ )}

Median age at inclusion (Range)

68

(54-81)

Median PSA ng/ml (Range)

984

(72-2678)

ECOG Performance status, n (\%)

0

1

3

12

0

(20)

2

Sites of metastasis, n (\%)

Bone

12

10

Lymph node

0

\section{Liver}

3

Mean time with metastatic disease before enrolment,

months

Gleason score, n (\%)

2-6

0

7

4

8-10

9

(27)

Not available

(13)

(20)

2 
Table 1C, Side effects Phase 1

\section{Table 1C, Side effects (patient $\mathbf{n = 1 5}$ )}

CTC GRADE

2

3

Dose level 0

Symptom

No

$(n=3)$

Pain

2

Fatigue

2

Dose level $1 \quad$ Symptom

$(n=3)$

Pain

Fatigue

Nausea

Alopeci

Neuropati

Infection

Loss of

appetite

Anaemia

Dose level 2 Symptom

$(\mathrm{n}=3)$

Pain

Fatigue

Nausea

Alopeci

Loss of

No

1

1

1

1

2

2

1

1

1

appetite

Mucositis

Oedema

\section{1}

No

No

2

1

1

3

1

2

Diare

Trombopeni

Dose level 3 Symptom

$(\mathrm{n}=3)$

Fatigue

Alopeci

Infection

Diare

Anaemia

Dose level $4 \quad$ Symptom

$(\mathrm{n}=3)$

Fatigue

Alopeci

Infection

Oedema

Diare

Dyspnoe

$\begin{array}{rr}\text { No } & \\ 1 & \\ 2 & \\ 1 & \\ 1 & \\ 1 & \\ \text { No } & \text { No } \\ 1 & \\ 1 & 1 \\ 1 & 1 \\ & \end{array}$


Table 2 - Patient characteristics Phase II

\begin{tabular}{|lll|}
\hline Table 2 - Patient characteristics (patient $\mathbf{n = 5 0}$ ) & & \\
\hline Median age at inclu sion (Range) & 64 & $(49-77)$ \\
Median PSA ng/ml (Range) & 448 & $(12-4580)$ \\
ECOG performance status, n (\%) & \\
$\quad 0$ & 21 & $(42)$ \\
1 & 26 & $(52)$ \\
2 & 3 & $(6)$ \\
Sites of metastases, n (\%) & & \\
$\quad$ Bone & 49 & $(98)$ \\
Lymph node & 24 & $(48)$ \\
Liver & 0 & $(0)$ \\
Lung & 4 & $(8)$ \\
Mean time with metastatic disease before enrollment, months & 22 & $(1-92)$ \\
Gleason Score, $n(\%)$ & & \\
$2-6$ & 4 & $(8)$ \\
7 & 9 & $(18)$ \\
$8-10$ & 21 & $(42)$ \\
Not available & 16 & $(32)$ \\
\hline
\end{tabular}


Table 3 - Side effects Phase II

\begin{tabular}{|c|c|c|c|c|c|}
\hline \multirow[b]{2}{*}{ Symptom, No (\%) } & \multicolumn{3}{|c|}{ CTC-grade } & \multirow{2}{*}{\multicolumn{2}{|c|}{4}} \\
\hline & 1 & 2 & 3 & & \\
\hline Nausea & $16(32)$ & 7 (14) & 1 (2) & 0 & $(0)$ \\
\hline Vomiting & $11(22)$ & $3(6)$ & $2(4)$ & 0 & $(0)$ \\
\hline Alopecia & $18(36)$ & $17(34)$ & $0 \quad(0)$ & 0 & (0) \\
\hline Infection & $4(8)$ & 9 (18) & 9 (18) & 0 & $(0)$ \\
\hline Fever and neutropenia & $0 \quad(0)$ & 1 (2) & $4(8)$ & 2 & (4) \\
\hline Diarrhea & $14(28)$ & $2(4)$ & $0 \quad(0)$ & 0 & $(0)$ \\
\hline Neuropathy & $15(30)$ & $4 \quad(8)$ & 2 (4) & 0 & (0) \\
\hline Lose of appetite & $13(26)$ & 9 (18) & $0 \quad(0)$ & 0 & $(0)$ \\
\hline Dyspnea & $10(20)$ & $4(8)$ & 1 (2) & 0 & $(0)$ \\
\hline Edema & $2(4)$ & $4(8)$ & $2(4)$ & 0 & $(0)$ \\
\hline Neutropenia & $0 \quad(0)$ & $7(14)$ & $25(50)$ & 12 & $(26)$ \\
\hline
\end{tabular}


Table 4 - Results Phase II

Table 4 - Results (patient $\mathbf{n = 5 0}$

Tumor response (RECIST), n (\%) $\mathrm{N} \quad \%$

Partial remission

$12 \quad 50$

Stable disease

20

Progressive disease

13

Not evaluable

17

Total with measurable tumors

PSA response $\geq 50 \%, \mathrm{n}(\%)$

48

PSA response $\geq 75 \%, \mathrm{n}(\%)$

$37 \quad 74$

$23 \quad 46$


Table 5. Painresponse

\begin{tabular}{|c|c|c|c|}
\hline \multirow{6}{*}{ CTC Grade } & & $\begin{array}{l}\text { Pre-treatment } \\
\text { No. Patients }\end{array}$ & $\begin{array}{l}\text { Pain after } 8 \text {. course } \\
\text { No. Patients }\end{array}$ \\
\hline & 0 & 30 & 45 \\
\hline & 1 & 9 & 0 \\
\hline & 2 & 8 & 4 \\
\hline & 3 & 2 & 0 \\
\hline & 4 & 0 & 0 \\
\hline Total & & $49 *$ & $49 *$ \\
\hline
\end{tabular}

The pain response was statistical significant. 50\% extra patients had reported no pain CTC $=$ grade 0 after treatment with 8 courses of DGP.

* One patient did not fill out the pain diary. 
Figure 1 legend:

Kaplain-Meier estimation of overall survival - mean OS 13.9 months.

Figure 1 - Overall survival

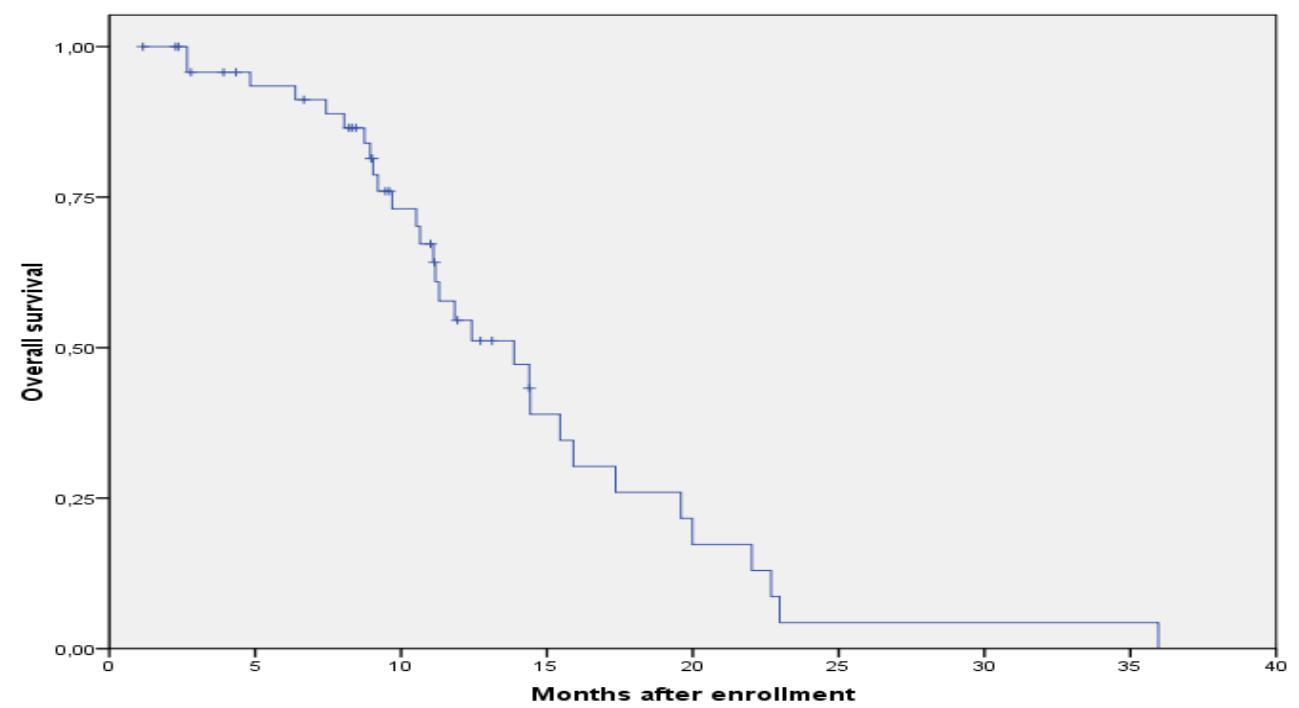

Kaplan-Meier estimate of overall survival. 
Figure 1 legend:

Kaplain-Meier estimation of overall survival - mean OS 13.9 months. 